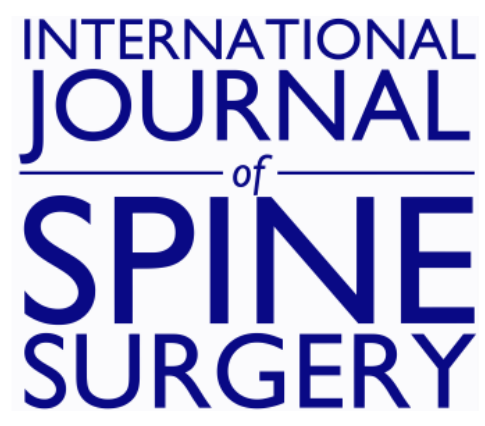

\title{
The Use of Image-Guided Navigation Systems During Spine Surgeries in Saudi Arabia: A Cross-Sectional Study
}

\author{
THAMER M. ALRAIYES, ABDULRHMAN ALRAJHI, HUSSAM ABOU-AL-SHAAR, \\ ABDULRAHMAN ZEKRY, NAIF M. ALOTAIBI, SAMI ALEISSA and ZAYED ALZAYED
}

Int J Spine Surg 2020, 14 (6) 1016-1022

doi: https://doi.org/10.14444/7152

http://ijssurgery.com/content/14/6/1016

This information is current as of April 26, 2023.

Email Alerts Receive free email-alerts when new articles cite this article. Sign up at:

http://ijssurgery.com/alerts

The International Journal of Spine Surgery

2397 Waterbury Circle, Suite 1,

Aurora, IL 60504, Phone: +1-630-375-1432 


\title{
The Use of Image-Guided Navigation Systems During Spine Surgeries in Saudi Arabia: A Cross-Sectional Study
}

\author{
THAMER M. ALRAIYES, MD, FRCSC, ${ }^{1}$ ABDULRHMAN ALRAJHI, MD ${ }^{2}$ HUSSAM ABOU-AL-SHAAR, \\ MD,${ }^{3}$ ABDULRAHMAN ZEKRY ${ }^{2}$ NAIF M. ALOTAIBI, MD, MSC, FRCSC ${ }^{4}$ SAMI ALEISSA, MD ${ }^{5}$ ZAYED \\ ALZAYED, MD ${ }^{1}$ \\ ${ }^{I}$ Department of Orthopaedics, King Faisal Specialist Hospital \& Research Centre Riyadh, Saudi Arabia, ${ }^{2}$ Department of Orthopaedics, King Saud University \& \\ Hospitals, Riyadh, Saudi Arabia, ${ }^{3}$ Department of Neurosurgery, Hofstra Northwell School of Medicine, Manhasset, New York, ${ }^{4}$ National Neuroscience Institute, \\ King Fahad Medical City, Ministry of Health, Riyadh, Saudi Arabia, ${ }^{5}$ Department of Surgery, Division of Orthopedics, King Abdulaziz Medical City, National \\ Guard Health Affairs, Riyadh, Saudi Arabia
}

\begin{abstract}
Background: We used a cross-sectional study design (questionnaire) to investigate the use of image-guided navigation (IGN) in Saudi Arabia and explore possible differences in implementing IGN for daily practice.

Methods: An internet-based survey was sent to all spine surgeons who are practicing in Saudi Arabia (orthopedics or neurosurgery). The survey is composed of 12 items that collected demographic and academic data.

Results: Ninety-nine answered the questionnaire from 197; 80\% were from Riyadh, the capital, and 50\% were consultants (attending physicians). Orthopedic surgeons were almost $60 \%$ of responders compared to $40 \%$ neurosurgeons. The use of navigation in Saudi hospitals was high $(76.8 \%)$. There was a significant difference between specialties in the preference of using navigation $(23.2 \%$ for orthopedics versus $81.4 \%$ for neurosurgery, $P<.001)$ and routine use in surgical spine cases $(88.4 \%$ for neurosurgery versus $50.0 \%$ orthopedics, $P<.001)$. The majority of responders from neurosurgery learned to use navigation during residency compared to orthopedics responders $(51.2 \%$ versus $28.6 \%, P=.001$ ). More than $30 \%$ of orthopedics responders expressed they never learned navigation compared to only $4 \%$ of neurosurgery responders. The comfort level of $>75 \%$ with performing surgery using navigation was significantly different between specialties ( $25 \%$ for orthopedics versus $46.5 \%$ for neurosurgery, $P<.001$ ).

Conclusion: Saudi spine surgeons are among the highest users of IGN systems. The strong healthcare infrastructure and the availability of these devices across the country are among the most important factors for its prevalence. Enhancing surgical exposure and education of postgraduate trainees to use these tools, especially within orthopedics, could increase use and comfort level rates.
\end{abstract}

Other \& Special Categories

Keywords: image-guided navigation, IGN, minimally invasive surgery, MIS, three-dimensional, 3D, global, Saudi Arabia, spine

\section{INTRODUCTION}

The accurate placement of the spine pedicle screw is of utmost significance and researchers have been urging spine surgeons and specialists to enhance the approaches to enable accurate and safe instrumentations. ${ }^{1}$ As evidence has supported the use of pedicle screws instrumentation in the correction and stabilization of various spine conditions, misplacement complications (neurologic deficits, dural tears, pedicle fractures and vascular injuries) have been increasing. ${ }^{1-5}$ Since navigated spine surgeries were first described in the 1990s, image-guided surgeries have revolutionized the field of spinal instrumentation and opened a new era of safe spine surgery. The employment of intraoperative 3-dimensional neuro- navigation systems in spine surgeries has become a critical adjunct for spine surgeries and helps surgeons to ensure accurate screws placement rather than relying on anatomical landmarks and preoperative planning, with less radiation exposure. ${ }^{6-9}$

With the advancement of medical technology, market industries started playing an integral role in evolving state-of-the-art innovations, as evident by the increased use of image-guided navigation (IGN) over conventional methods. ${ }^{10,11}$ Several studies indicated that pedicle screw insertion accuracy could be significantly improved with IGN systems compared with conventional approaches. ${ }^{12}$ Several reports and meta-analysis studies documented the advantage of IGN compared to conventional modalities in decreasing the perforation risk, 
cerebrospinal fluid leakage, and radiation exposure with slightly increased operative time. ${ }^{13,14}$

Although IGN outcomes are reported by multicenter studies and meta-analyses, the adoption of this technology at a country level is still unknown. The Kingdom of Saudi Arabia is presently receiving an enormous support for its healthcare budget, creating a paradigm shift in the standards of health care and training of postgraduate medical trainees, especially within the "2030 Saudi Vision." Therefore, we aim in this study to investigate the current use of IGN in Saudi Arabia and explore possible differences in implementing IGN in spine surgery among orthopedic and neurosurgery faculty and trainees.

\section{METHODS}

With the assistance of clinical epidemiologists and spine surgery experts, we developed a 12-item survey (Table) in English (official study language in all Saudi medical schools) to assess the Saudi spine surgeons' use of IGN surgery as part of their clinical practice and to evaluate their attitudes toward it. The study was approved by our Research Ethics Committee at King Faisal Specialized Hospital and Research Centre. Surgeons were interviewed over a period of 6 months in 2017 through a web-based survey questionnaire, using Google Documents, and paper-based surveys distributed to all spine surgeons who are currently practicing in Saudi Arabia, through the Saudi Spine Society. Surgeons included in the study comprised both orthopedic surgeons and neurosurgeons.

The final questionnaire framed response options with closed-ended questions from which the respondent could choose 1 answer. An email was sent to all the spine surgeons within the Saudi Spine Society database, and a reminder email was sent few months following the initial email. As for the paper questionnaire, it was reserved for the surgeons who did not respond to the web-based questionnaire and were able to have the survey delivered to them in person (fewer than 10 surgeons). Data were gathered according to demographics (region, subspecialty), and other specific information (surgeon's level: resident, fellow, or consultant [attending physician], type of IGN used, government/private hospital practice).

Survey responses were deidentified and then collected into a Microsoft Excel database. Responses were converted to nominal categorical or ordinal variables. Pearson $\chi^{2}$ tests or Fisher exact tests were employed for comparisons between categorical variables. Statistical significance was set at $P<$ .05. All tests were 2-tailed. All statistical tests were performed using SPSS (version 21; IBM, Chicago, Illinois).

\section{RESULTS \\ Demographics}

From 197 surveys sent to all practicing spine surgeons (consultants, fellows, residents) we got 99 responses (response rate 50.2\%); among those responders, 79 were from Riyadh, the capital (Figure 1). The majority of responders $(50 \%)$ were consultants (attending physicians), while 30\% were assistant consultants or fellows. Orthopedic surgeons constituted almost $60 \%$ of responders compared to $40 \%$ who were neurosurgeons. Sixty-nine responders had more than 5 years in clinical experience and $70 \%$ worked in government hospitals.

\section{Use and Preference}

The use of IGN in Saudi hospitals was high (76.8\%) among responders. There were no differences between specialties (orthopedics versus neurosurgery) in the availability of IGN at their hospitals $(81.4 \%$ versus $73.2 \%, P=.472$; Figure $2)$. However, there were statistically significant differences between specialties in the preference of IGN use $(81.4 \%$ for neurosurgery versus $23.2 \%$ for orthopedics, $P<.001$ ) and routine use during spine cases $(88.4 \%$ for neurosurgery versus $50.0 \%$ for orthopedics, $P<.001$; Figure 3 ). The type of IGN device did not differ between specialties. Orthopedic surgeons had a higher preference rate of using IGN in revision cases $(20 \%$ versus $7 \%)$.

\section{Learning Time and Comfort Level}

The majority of neurosurgeons learned to use IGN during residency compared to orthopedics responders $(51.2 \%$ versus $28.6 \%, P=.001)$. More than $30 \%$ of orthopedic surgeons expressed that they "never learned to use navigation systems" compared to only $4 \%$ of neurosurgery responders. Interestingly, the comfort level $(>75 \%)$ with performing surgery using IGN was significantly different between specialties $(46.5 \%$ for neurosurgery versus $25.0 \%$ for orthopedics, $P<.001$ ). 
Table. The 12-item questionnaire used in the study.

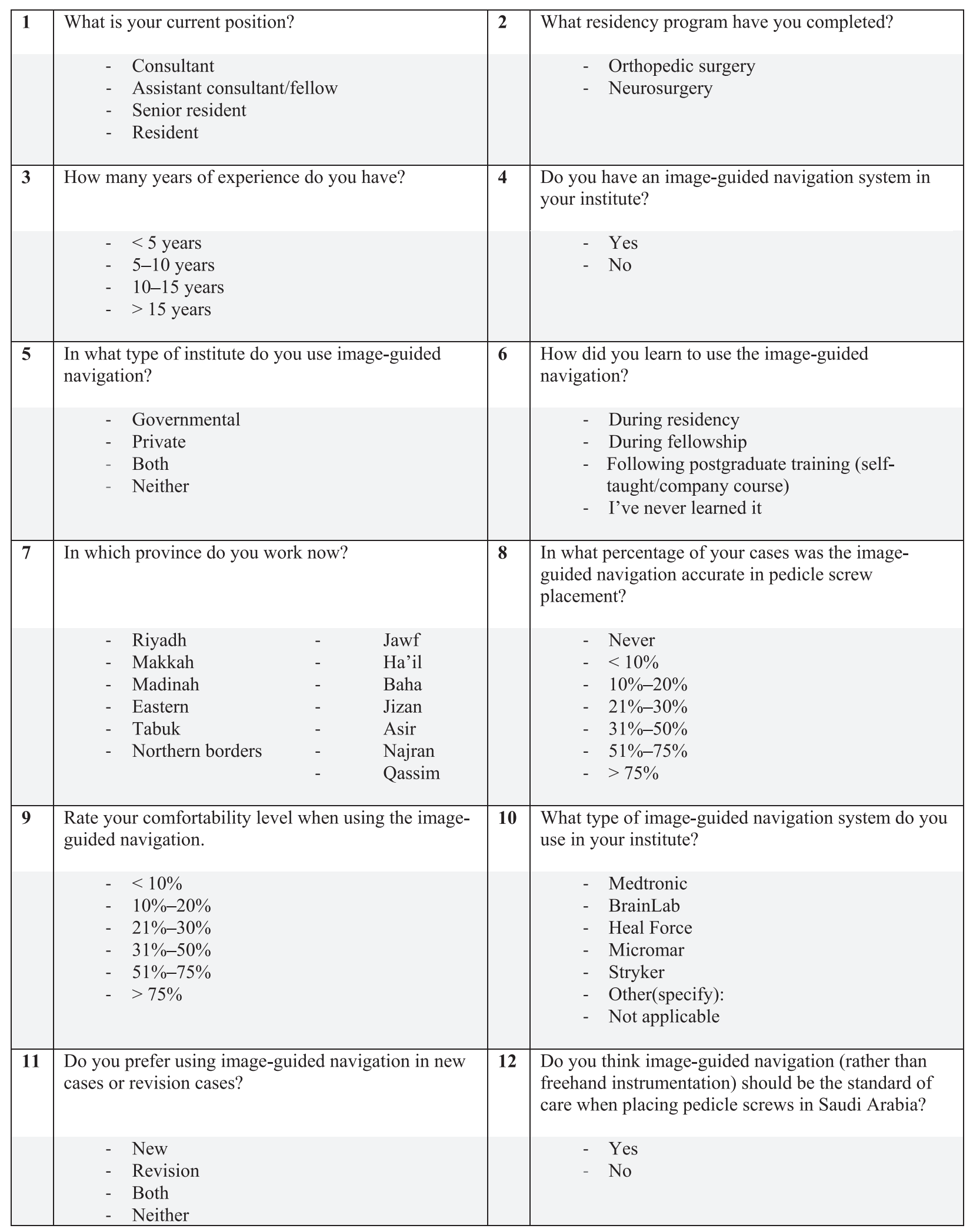




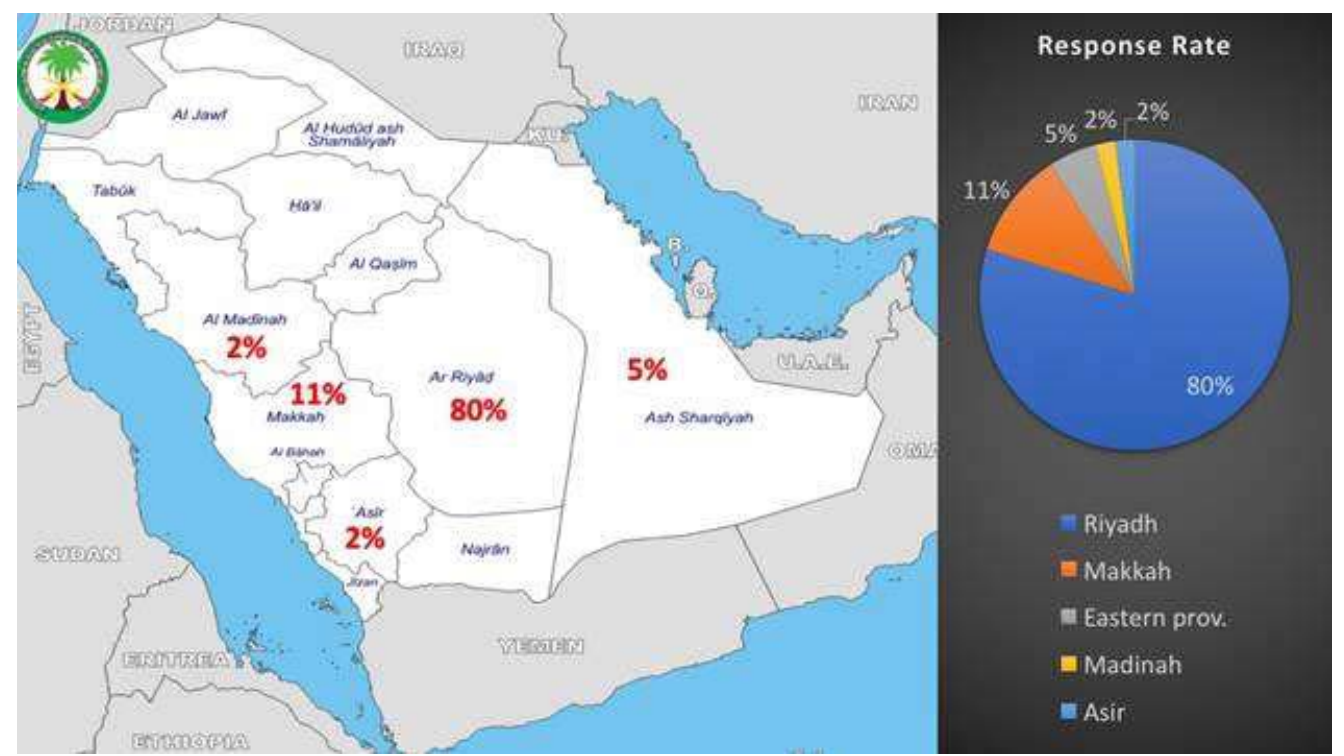

Figure 1. Map of Saudi Arabia showing the response rate per region.

\section{Accuracy Level}

Of all the responders, $38.4 \%$ reported an accuracy in their pedicle screw placement $>75 \%$ of the time; however, we don't know how this was determined by every responder. On the other hand, $37.4 \%$ said that such an answer was not applicable.

\section{IGN as Standard-of-Care Adjunct}

Most neurosurgeons (58\%) supported implementing IGN as a standard-of-care adjunct in spine surgery compared to only $20 \%$ of orthopedic surgeons. According to various open responses with this question, IGN was thought to be underused due to several factors: increased associated costs, lack of

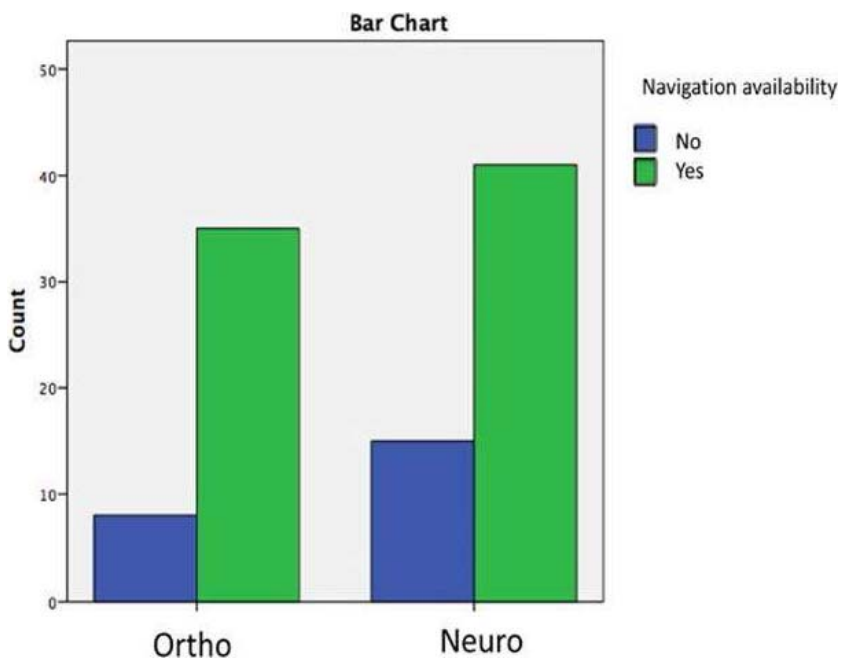

Figure 2. Bar chart demonstrating that there were no differences between specialties (orthopedics versus neurosurgery) in the availability of navigation at their hospitals. early exposure and training, and increase in the operating room time. Accuracy and radiation exposure were also a concern for responders and many surgeons were questioning its validity and whether it was cost efficient or not.

\section{DISCUSSION}

The use of IGN has become an essential part of the armamentarium for cranial surgeons for the past few decades. However, its adoption among spine surgeons remains largely limited. For decades, spinal fixation has been established using the freehand technique, which may lead to devastating errors and has inherent limitations. As the implica-

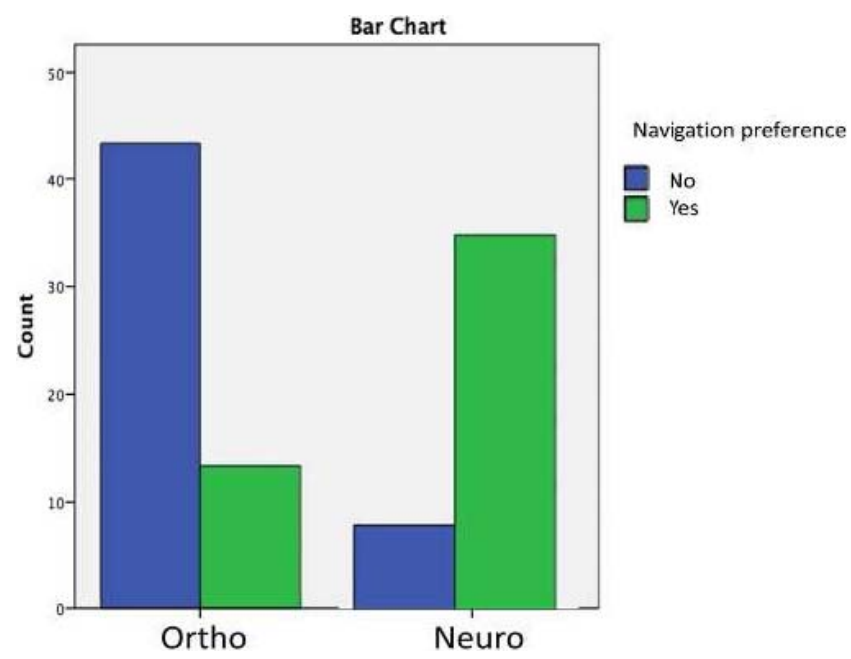

Figure 3. Bar chart showing preference of using navigation between specialties (orthopedics versus neurosurgery). 
tions of spinal fixation continues to rise for various conditions, including degenerative spinal disease, vertebral fractures, and deformity, the call for better placement strategies that limit iatrogenic neurovascular injuries was essential.

Since the introduction of spinal IGN in the early 1990s, the employment of IGN during spine surgeries has been steadily increasing, especially among complex deformity cases. ${ }^{6,8}$ Various studies and meta-analyses have documented the accuracy and safety profiles of IGN during spine surgeries. Tian et al depicted that computed tomography navigation, 2-dimensional fluoro-navigation, and 3-dimensional fluoro-navigation are significantly more accurate than the freehand technique. Similar results were reproduced by $\mathrm{Du}$ and colleagues. ${ }^{15,16}$ However, many spine surgeons remained reluctant regarding its use citing concerns with costs, radiation exposure, and operative time. ${ }^{17}$ Interestingly, IGN demonstrated significant reduction of intraoperative radiation exposure compared with the other conventional and navigation modalities. ${ }^{18}$ Moreover, it was found that IGN increased the surgical time by only 10 minutes, which is not significant compared to the major advantage of better anatomical delineation, improved accuracy, and reduced complications. ${ }^{18}$ This increased operative time is also learner-dependent with various studies documenting significant reduction of surgical time from 16 to 7 minutes over the course of 2 years as the learning curve of the surgeon improved. ${ }^{19}$

Despite the obvious advantage of IGN during spine instrumentation, the degree of its use among spine surgeons is still largely unknown. Our study aimed to identify the degree of its use and the factors that spine surgeons consider when employing this technique. Saudi Arabia is the largest Middle Eastern country by area and has an evolving healthcare system and strong infrastructure. Therefore, exploring the degree of IGN use will shed the light on the use of such relatively new advanced system in a developing nation and on important hidden factors related to its use among Saudi spine surgeons.

The survey included both orthopedic spine surgeons and neurosurgeons that perform spinal instrumentation procedures. The response rate was $50 \%$. As expected, the majority of responders $(80 \%)$ were located in the capital of Saudi Arabia, Riyadh, since it is known to have some of the best medical centers in the country. Interestingly, orthopedic surgeons were more likely to respond to the survey questionnaire compared to neurosurgeons $(60 \%$ versus $40 \%$ ). This observation is in accordance with Härtl et al who performed a worldwide survey among spine surgeons to assess the degree of IGN use across 5 geographic locations. ${ }^{17}$ The authors had a $20 \%$ response rate, with the majority of responders being orthopedic surgeons.

The use of the IGN system in Saudi Arabia was interestingly high $(76.8 \%)$, which is in the contrary to what Härtl and colleagues found in their study. The authors found that $66 \%$ of the surveyed surgeons never used IGN for spinal fusion surgery, $9 \%$ were routine users, and $25 \%$ were only selective users. This might be attributed to the strong healthcare budget in Saudi Arabia and the availability of IGN systems across the hospitals in the country in addition to the highlevel educational courses conducted for faculty and trainees.

Härtl and colleagues found that more than $40 \%$ of neurosurgeons use IGN frequently compared to $28 \%$ of orthopedic spine surgeons. ${ }^{17}$ Similarly, we found a statistically significant difference among the use rate between neurosurgeons and orthopedic surgeons $(88.4 \%$ versus $50.0 \%$, respectively, $P<$ .001 ), which might be attributed to early exposure of neurosurgeons to IGN devices during their residency compared to orthopedic surgeons $(51.2 \%$ versus $28.6 \%, P=.001)$. Despite the increasing popularity using IGN, a few issues remain for many spine surgeons worldwide including the operating time and its effect on the workflow. In their retrospective study, Miller and Fabiano compared the results between IGN and traditional use of fluoroscopy. The authors found similar operative time between the 2 groups, with less blood loss when IGN was used. ${ }^{20}$

Our study is, however, limited by several factors. First, we adopted a closed-ended survey with predesigned answer options, which may not detect the different opinions among Saudi spine surgeons. Second, we intended to send the survey to all spine surgeons and trainees across the country; however, we realize that we might have missed some surgeons who therefore did not have the opportunity to complete the survey. Third, surgeons' experience is variable among our responders with some surgeons having more than 20 years of experience and others still in their training. Fourth, the incidence of 
malpositioned hardware was not included in our questionnaire. Fifth, the data collected about the use of IGN did not include the type of surgery performed (trauma, deformity, degenerative disease, etc). Finally, the response rate was $50 \%$; thus, the possibility that surgeons with a specific opinion may have been more likely to respond cannot be eliminated.

\section{CONCLUSION}

The advancement of medical technology and navigation techniques for spinal instrumentation has resulted in better accuracy and reduced complications and radiation exposure compared to the traditional freehand instrumentation. Our results documented that Saudi spine surgeons are among the highest users of IGN systems during spine surgeries and highlight significant differences in the use of IGN among specialties in Saudi Arabia. The strong healthcare infrastructure and the availability of these devices across the country, along with the educational courses, are among the most important factors for its prevalence among Saudi spine surgeons.

\section{ACKNOWLEDGMENTS}

The authors thank Daipayan Guha, MD, PhD, FRCSC for his help to generate our questionnaire. Also, we thank Fatmah Ismail Alnahari, Nusaybah Yasser Ali Morya, and Raghad Khalid Saad Alwagdani (medical students) for their assistance during data collection.

\section{REFERENCES}

1. Esses SI, Sachs BL, Dreyzin V. Complications associated with the technique of pedicle screw fixation. A selected survey of ABS members. Spine (Phila Pa 1976). 1993;18(15):2231-2238; discussion 2238-2239.

2. Boos N, Webb JK. Pedicle screw fixation in spinal disorders: a European view. Eur Spine J. 1997;6(1):2-18.

3. Davne SH, Myers DL. Complications of lumbar spinal fusion with transpedicular instrumentation. Spine (Phila $\mathrm{Pa}$ 1976). 1992;17(suppl 6):S184-S189.

4. Soultanis KC, Sakellariou VI, Starantzis KA, Papagelopoulos PJ. Late diagnosis of perforation of the aorta by a pedicle screw. Acta Orthop Belg. 2013;79(4):361-367.

5. Castro WH, Halm H, Jerosch J, Malms J, Steinbeck J, Blasius S. Accuracy of pedicle screw placement in lumbar vertebrae. Spine (Phila Pa 1976). 1996;21(11):1320-1324.

6. Foley KT, Smith MM. Image-guided spine surgery. Neurosurg Clin N Am. 1996;7(2):171-186.
7. Kalfas IH, Kormos DW, Murphy MA, et al. Application of frameless stereotaxy to pedicle screw fixation of the spine. $J$ Neurosurg. 1995;83(4):641-647.

8. Nolte L, Zamorano L, Arm E, et al. Image-guided computer-assisted spine surgery: a pilot study on pedicle screw fixation. Stereotact Funct Neurosurg. 1996;66(1-3):108-117.

9. Austin MS, Vaccaro AR, Brislin B, Nachwalter R, Hilibrand AS, Albert TJ. Image-guided spine surgery: a cadaver study comparing conventional open laminoforaminotomy and two image-guided techniques for pedicle screw placement in posterolateral fusion and nonfusion models. Spine (Phila Pa 1976). 2002;27(22):2503-2508.

10. Waschke A, Walter J, Duenisch P, Reichart R, Kalff R, Ewald C. CT-navigation versus fluoroscopy-guided placement of pedicle screws at the thoracolumbar spine: single center experience of 4,500 screws. Eur Spine J. 2013;22(3):654-660.

11. Helm PA, Teichman R, Hartmann SL, Simon D. Spinal navigation and imaging: history, trends, and future. IEEE Trans Med Imaging. 2015;34(8):1738-1746.

12. Fraser J, Gebhard H, Irie D, Parikh K, Hartl R. Iso-C/3dimensional neuronavigation versus conventional fluoroscopy for minimally invasive pedicle screw placement in lumbar fusion. Minim Invasive Neurosurg. 2010;53(4):184-190.

13. Amiot LP, Lang K, Putzier M, Zippel H, Labelle H. Comparative results between conventional and computerassisted pedicle screw installation in the thoracic, lumbar, and sacral spine. Spine (Phila Pa 1976). 2000;25(5):606-614.

14. Arand M, Hartwig E, Hebold D, Kinzl L, Gebhard F. Precision analysis of navigation-assisted implanted thoracic and lumbar pedicled screws. A prospective clinical study [in German]. Unfallchirurg. 2001;104(11):1076-1081.

15. Tian NF, Huang QS, Zhou P, et al. Pedicle screw insertion accuracy with different assisted methods: a systematic review and meta-analysis of comparative studies. Eur Spine J. 2011;20(6):846-859.

16. Du JP, Fan Y, Wu QN, Wang DH, Zhang J, Hao DJ. Accuracy of pedicle screw insertion among 3 image-guided navigation systems: systematic review and meta-analysis. World Neurosurg. 2018;109:24-30.

17. Härtl R, Lam KS, Wang J, Korge A, Kandziora F, Audige L. Worldwide survey on the use of navigation in spine surgery. World Neurosurg. 2013;79(1):162-172.

18. Gebhard FT, Kraus MD, Schneider E, Liener UC, Kinzl L, Arand M. Does computer-assisted spine surgery reduce intraoperative radiation doses? Spine (Phila Pa 1976). 2006;31(17):2024-2027; discussion 2028.

19. Kendoff D, Citak M, Gardner MJ, Stubig T, Krettek C, Hufner T. Intraoperative 3D imaging: value and consequences in 248 cases. J Trauma. 2009;66(1):232-238.

20. Miller JA, Fabiano AJ. Comparison of operative time with conventional fluoroscopy versus spinal neuronavigation in instrumented spinal tumor surgery. World Neurosurg. 2017; 105:412-419.

Corresponding Author: Thamer M. Alraiyes, MD, FRCSC, Orthopedic Surgery Department, King Faisal Specialist Hospital \& Research Centre, MBC 77, KFSHRC, Riyadh, Kingdom of Saudi 
Arabia. Phone: 00966-11-4427591; Fax: 00966-11442759; Email: talraiyes@kfshrc.edu.sa.

Published 22 January 2021

This manuscript is generously published free of charge by ISASS, the International Society for the Advancement of Spine Surgery. Copyright (C) 2020 ISASS. To see more or order reprints or permissions, see http://ijssurgery.com. 